\title{
A Study to Assess the Workload of Lady Health Workers in Khanpur UC, Pakistan by Applying WHO's WISN Method
}

\author{
By Nadeem Sajjad Kayani* \\ Samina Naeem Khalid \\ Shamsa Kanwal
}

In this study, we used WHOs WISN approach to estimate the workload of LHWs of Khanpur UC, Khyber Pakhtunkhwa, Pakistan. After its collection, the data was converted into meaningful information and the available working time was calculated. Health service activities, support activities and additional activities were subdivided based on the available statistics. Basic staff requirements, individual allowance factors and category allowance factors were calculated using WISN followed by the total LHWs staffing requirements and the workload for 2014. The WISN difference measure indicated that the health unit was relatively overstaffed while the ratio measure and workload pressure came out to be 1.19 and $-19.89 \%$ respectively. Results showed that 13 LHWs could perform the same amount of work performed by 16. This study suggests that the balance between the workload and LHWs staffing requirements can be achieved by redistributing three out of 16 LHWs in un-served parts and by increasing the number of households visited from 07 to 09 per day per $L H W$.

Keywords: Workload Indicator of Staffing Needs, Activity Standards, Lady Health Workers staffing, Human Resource Management.

\section{Introduction}

Human resources play a very important role in delivering health care services. Hence they are a critical determinant of the health system's effectiveness and efficiency. Nowadays increasing the demand for the efficient delivery of improved health care services is adding to the pressure on health systems (Hossain and Alam 1999). As a result, this burden is giving rise to the cost of provision of health care services (Das et al. 2013). Both developed and developing countries are looking at more efficient ways to increase the accessibility of their population to the health services they provide. In this context, a health workforce can be very helpful in improving the health profile of a nation if managed and used meritoriously. This inevitably calls for a close examination of the distribution of the health workforce and for the ensuring of their full and effective utilization. Workforce management can be improved by hiring the required number of people with the right skill set and attitude. However, inappropriate use of these

\footnotetext{
* Deputy Project Manager, Health Service Academy (HSA), Ministry of National Health Services, Government of Pakistan, Pakistan \& Post Graduate Student, Queen Margret University, UK.

$\dagger$ Associate Professor, Health Services Academy (HSA), Ministry of National Health Services, Government of Pakistan, Pakistan.

* PhD Scholar, Polytechnic University of Hong Kong, Hong Kong.
} 
health personnel in inappropriate proportions in wrong geographical places often does not make any significant contribution to the provision of health care services (Delanyo 2005, Namaganda 2004). Oftentimes, it leads to problems like shortage of right skill sets and generates staffing inequalities which ultimately creates problems for managers and renders the resources required to fulfill the demand for services by the population inadequate (Buchan 1999, Namaganda 2004). Therefore, a proper staffing level with appropriate skills for primary care approach in terms of delivering health care services efficiently and timely is critical (Buchan et al. 2000).

Pakistan stands $6^{\text {th }}$ in the list of the most populous countries in the world with a total population of around 182 million (Khan et al. 2012). To meritoriously respond to the unmet health needs of the country's rural areas and urban slums, a cadre of Lady Health Workers (LHWs) was initiated in 1994, primarily for the rural areas (Khan 2011, Shaikh and Hatcher 2004). This cadre was created in order to extend primary health care services at a household level like outreach services, through recruiting and deploying females within their own local community to create the awareness and changing the attitude regarding basic health issues, family planning and establishing a comprehensive grass roots level system for effective and efficient provisions of primary health care throughout the country. The LHWs are selected on the basis of the following criteria: 1) Local Resident; 2) Middle School Pass; 3) Preferably Married; 4) Age $\leq 18$ years; and 5) Recommended by/acceptable to the community. Basically LHWs are appointed in their own local community where they live and are familiar with its people and setting. This helps them in gaining trust and confidence of their people. They generally do not need to travel to other cities to visit households because other cities have generally their own LWHs. According to the National Program for Family Planning \& Primary Health Care in (NP for FP and PHC) ${ }^{1}$ Pakistan, each single LHW is recruited for approximately 1,000 people, or 150 households in a month and she visits 5 to 7 houses daily (Wajid et al. 2013). She visits all households under her charge at least once in a month and records all the required information in registers and monthly reports which she keeps with her during her visits. She submits these reports to the affiliated Basic Health Unit (BHU). The lady health supervisor (LHS) collects all these reports from the LHWs, under her supervision and sends this information to the district coordinator by the end of the second week of the preceding month which ultimately reaches the provincial coordinator and national coordinator by the end of third and fourth week of the same month respectively. The scope of her work and responsibility includes health education in terms of antenatal care and referral, immunization services and support to community mobilization, provision of family planning and basic curative care (Hafeez et al. 2011, Sarfraz and Hamid 2014, Wajid et al. 2013). Currently the Lady Health Workers Programme (LHWP) is comprised of approximately 100,000 LHWs (Wajid et al. 2013).

\footnotetext{
${ }^{1}$ National Program for Family Planning \& Primary Health Care, Pakistan (NP for FP \& PHC). Retrieved from http://goo.gl/Ua2T3x. [Accessed: 10 September 2105]
} 
Like many other developing countries, the distribution of health and wealth is not equal throughout the whole country. It has been observed and documented at various occasions that the distribution of the available LHWs in a unit health facility with right skills mix is also inequitable. Wrong allocation and wrong distribution of LHWs may cause them to spend too much time on activities in the wrong geographical locations and make a very limited contribution in uplifting the health care profile of the country (Mugisha and Namaganda 2008). Therefore, efficient management of this health workforce is seen as a challenge to the country's health system. The quality of the service provided by LHWs and their staffing needs in the public health sector depends on the scope of its services provided by the health facility as well as their workload (Shipp 1998). In order to ensure the provision of quality services, this workforce is needed to be used effectively and efficiently in the right place considering their skill mix. Therefore, the workload of LHWs needs to be estimated accurately.

Various methods have been used to calculate the workforce needed which includes practitioner-to-population ratios, queuing theory, case-load profiling, treatment care standards, temporal patterns as well as judgments of experts and professionals (Hagopian et al. 2012, Hurst 2006, Schoo et al. 2008).

The method utilized in this study is the Workload Indicators of Staffing Needs (WISN), developed as an operational tool in 1984 by P.J. Shipp initially to project the workforce requirement for planning human resources strategically (Shipp 1998). The use of this method continued in different countries in a number of applications (Kolehmainen and Shipp 1990, Shipp 1998) and was continuously developed and improved till 1998 when it was adopted and promoted by the World Health Organization (WHO) to assess the optimal allocation and deployment of the workforce (Das et al. 2013, Daviaud and Chopra 2008, Hossain and Alam 1999, Kolehmainen-Aitken 2009). Although it is time-intensive but it provides more accurate results and it is really helpful in planning actions, policy and development (Das et al. 2013, Hagopian et al. 2012, Musau et al. 2008). This study reports on the use of the WISN method to estimate the workload of LHW working in the Khanpur UC, Pakistan. LHWs are the backbone of the National Program on Primary Health Care and Family Planning in Pakistan. For the community, they are the first contact/primary source for any health advice. LHWs are the critical determinant of the quality and quantity of the health care services delivery (Hafeez et al. 2011, Wajid et al. 2013). They were initially launched in Pakistan with a certain set of job responsibilities. Gradually, various other assignments have been added to LHW's portfolio at primary health care levels in addition to their initially assigned job which might have added to their workload pressure. Therefore, determining the staffing requirement of LHWs and their workload is very important.

\section{Objectives}

The objectives of this pilot study are 1) to calculate the LHWs staff required in Khanpur UC to cope with the present workload by applying the WISN method, and 2) to estimate the workload pressure of LHWs by applying the the WISN approach. 


\section{Study Area}

This study was conducted in Khanpur UC, District Haripur in the Khyber Pakhtunkhwa (KPK) province in Pakistan (Figure 1). This was chosen because reliable service statistics on the various activities performed by LHWs cadre were available for the study area where about 20,000 people of the population is served by 16 LHWs, each one visiting about 07 household per day. However, the demand of about 12,500 people in Khanpur UC is still unmet because of the unbalanced supply/distribution of LHWs compared to their staffing needs. LHWs staff distribution in the study area is inequitable, thing which ultimately is affecting the quality of primary health care services being provided there. Therefore, there is a demand of 09 more LHWs by the Lady Health Supervisor (LHS) in the Khanpur UC to cover the unserved population. LHWs move from one house to the other in a pre-identified pattern for the provision of services entrusted upon her. The time required for activity on a daily basis and movement among households may be affected by the topography, climate and the density of the population in the area. These factors had a minimal effect in the study area. However, this affect may vary from region to region and significant/reasonable impact might be experienced in northern, southern and eastern parts of the country.

Figure 1. Map Showing the Special Location of Study Area

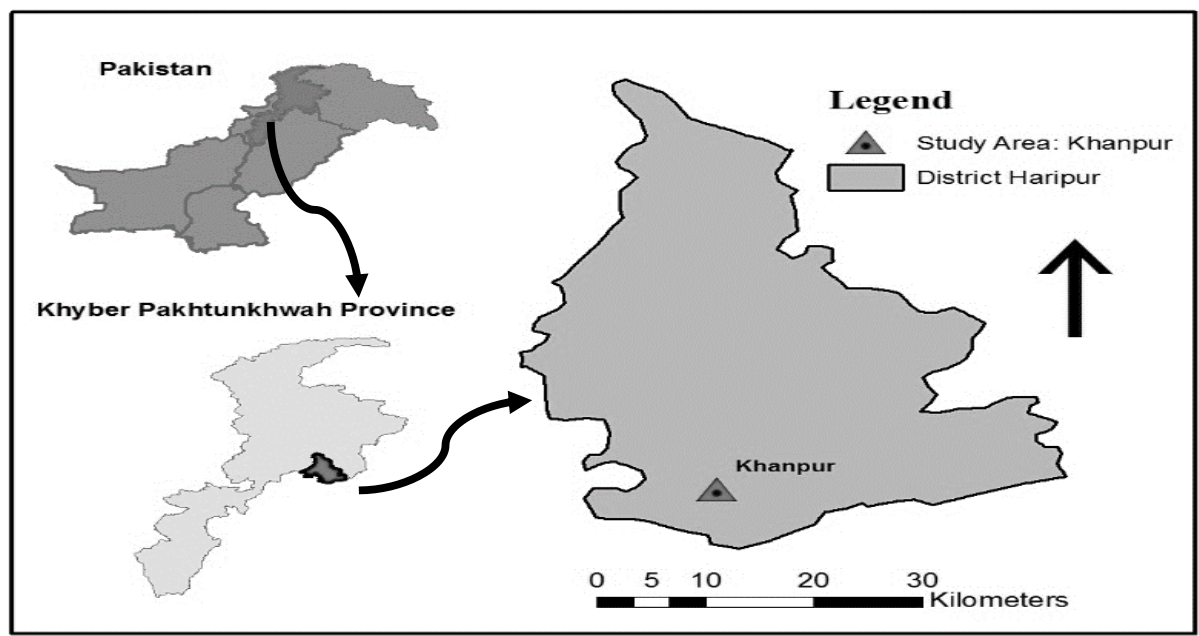

Source: Authors' work using ArcGIS 10x software.

\section{Methodology}

The health facility type selected for the workload estimation was primary care community outreach services and LHWs working in the community of Khanpur UC as priority health worker's cadre. To assess the workload indicators of staffing needs, LHWs at Khanpur, UC were interviewed in detail. The methodology to calculate the LHWs staffing requirement and workload consisted of the following series of steps as per the WISN method as illustrated in Figure 2. 
Step 1: Determining the cadre and health facility type

LHWs were selected as a priority cadre type in a primary health care facility unit.

\section{Step 2: Identification of the activities carried out by the LHWs}

As a standard, an LHW is assigned to visit 07 household per day, which requires about $245 \mathrm{~min}$. In addition to visiting households, LHWs carry out various other activities in their service areas. A comprehensive list of their activities was adopted from Hafeez et al. (2011) who provided a detailed insight into the different kind of health services delivered by the LHWs in Pakistan. The activities to be performed by LHWs on daily basis were consolidated as awareness, counseling, advice/referral notes, distribution of products and record keeping. These translations were used as a baseline for the calculation of workload. This list was further updated during the survey conducted for data collection. The validity and reliability of results depend on the accuracy of the input data. A team was composed to collect the data, interview of the LHWs and ensure the collection of quality data. 16 LHWs, one LHS and one expert from the selected health facility cadre in Tehsil Headquarters (THQs), Khanpur were interviewed in detail.

Figure 2. Methodology Flow Chart for Workload Estimation
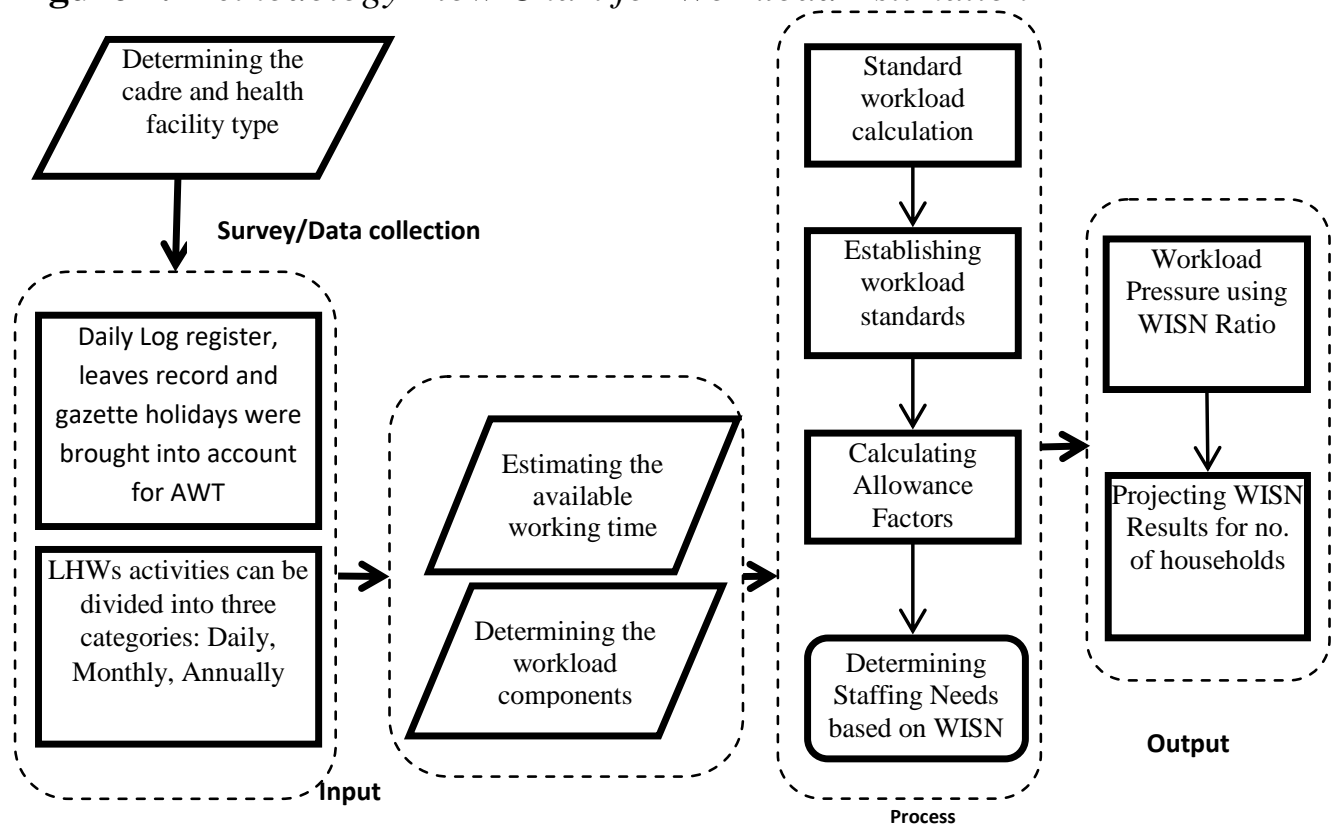

Source: WHO 2010.

Step 3: Setting activity standards for the identified workload components of LHWs

This step was carrying a two-pronged approach: i) observing the activities being carried out by LHWs and updating the list; and ii) estimating the time taken by each particular activity. Activity and allowance standards for each of the activities were set. Duties of LHWs were deeply studied, analyzed and 
aggregated into the following three main workload groups based on the available statistics, as per WISN requirement: a) Health service activities, b) Support activities and c) Additional activities. Each group encompassed different health activities known as workload component, as given in Table 1. All this data was converted into meaningful information for WISN based calculations of staffing requirement and their workload.

Table 1. Priority Health Workers Categories and Health Facilities Type

\begin{tabular}{|c|c|c|}
\hline Workload group & Workload component & Time Spent on each activity \\
\hline \multirow{7}{*}{$\begin{array}{l}\text { Health services } \\
\text { activities of ALL } \\
\text { LHWs } \\
\text { (Per Day } \\
\text { Activities) }\end{array}$} & 1. Visit to a household & \\
\hline & - Awareness & $5 \min$ \\
\hline & - Counselling & $10 \mathrm{~min}$ \\
\hline & - Distribution of products & $5 \mathrm{~min}$ \\
\hline & - Referral notes & $5 \mathrm{~min}$ \\
\hline & - Travel Time per household & $5 \mathrm{~min}$ \\
\hline & - Record keeping & $5 \min$ \\
\hline \multicolumn{2}{|c|}{ Total time required to visit 07 households } & $(35 x 7=245 \mathrm{~min}) 4.08$ hours $/$ day \\
\hline \multirow{5}{*}{$\begin{array}{l}\text { Support } \\
\text { activities of ALL } \\
\text { LHW } \\
\text { (Per Month } \\
\text { Activities) }\end{array}$} & $\begin{array}{l}\text { 1. Meeting of the Sehat } \\
\text { Committee: } 01 \text { meeting per } \\
\text { month }\end{array}$ & $60 \mathrm{~min}$ \\
\hline & $\begin{array}{l}\text { 2. Meeting of Women } \\
\text { Committee: } 01 \text { meeting per } \\
\text { month }\end{array}$ & $120 \mathrm{~min}$ \\
\hline & $\begin{array}{l}\text { 3. School Visit: } 01 \text { per month } \\
(50 \text { minutes per school) ( } 03 \\
\text { schools } x 60)\end{array}$ & $180 \mathrm{~min}$ \\
\hline & $\begin{array}{l}\text { 4. Visit to the THQ once a } \\
\text { month }\end{array}$ & $420 \mathrm{~min}$ \\
\hline & $\begin{array}{l}\text { 5. Supervisory visits and } \\
\text { coordinating with district and } \\
\text { tehsil management } 30 \\
\text { min/month ( } 6 \text { hours) }\end{array}$ & $30 \mathrm{~min}$ \\
\hline \multicolumn{2}{|l|}{ Total time } & 13.5 hours/month \\
\hline \multirow{4}{*}{$\begin{array}{l}\text { Additional } \\
\text { activities of ALL } \\
\text { LHW } \\
\text { (Per Year } \\
\text { Activities) }\end{array}$} & $\begin{array}{l}\text { 1. Polio Campaigns ( } 8 \text {, each } \\
\text { campaign spread over } 4 \text { days) }\end{array}$ & 32 days \\
\hline & 2. Measles Campaign & 14 days \\
\hline & 3. MNCH Program ${ }^{*}$ & 06 days \\
\hline & $\begin{array}{l}\text { 4. Giving information to } \\
\text { researchers, academicians etc. }\end{array}$ & 1.71 days \\
\hline \multicolumn{2}{|l|}{ Total time } & 370 hours/annum \\
\hline
\end{tabular}

Source: Authors' calculations.

Note: "MNCH (Maternal, Neonatal \& Child Health) is a national program run by the Ministry of Health of the Government of Pakistan to bring improvements in health indicators like IMR, MMR, TFR etc. Pakistan is signatory to several international agreements regarding improving $\mathrm{MNCH}$. Most notably, the Government is committed to achieve the Millennium Development Goals (MDGs) in MNCH.

Activity standards were set per individual activity in each workload component. Activity standard is the time required by a well-trained staff 
member to perform a health service activity to acceptable standards (Shipp 1998). It is set for the type of health service activities for which the annual workload cannot be estimated directly from their service statistics. These standards are of two types i.e. Individual Allowance Standard (IAS) and Category Allowance Standard (CAS), defined as follows:

1. Individual allowance standards (IAS): are a set of health service activities performed by either only one staff member or a certain number of staff members.

2. Category allowance standards (CAS): are a set of health service activities performed by all staff members of the same health cadre. For example, all LHWs spend 35 minute per household for the provision of primary health care services.

An allowance factor estimated for support activities is called Category Allowance Factor (CAF) and the one calculated for additional activities is called Individual Activity Factor (IAF). These are calculated as follows:

$$
\begin{aligned}
& \text { CAF }=1 /\left[1-\left(\frac{\text { Total CAS }}{100}\right)\right] \\
& I A F=I A S / A W T
\end{aligned}
$$

Step 4: Calculation of the available working time for LHWs

Available working time (AWT) is the amount of time available to a staff category in a year for the delivery of health services (Shipp 1998). AWT, also known as actual time spent by a health worker at work, depends on number of leaves used in holidays, off duties, official leave and other absences. Data on LHW's absences was gathered by reviewing the office records obtained from the LHS working in THQ for the period of one year from i.e. January 2014 to December 2014 and interviewing the LHS and in-charge of the THQs. This was done purposely in order to reflect the LHW's current staffing condition. AWT for LHWs was then obtained as follows:

$$
\text { Total available working time }=A W T=[A-(B+C+D+E)] x F
$$

where,

$\mathrm{A}=$ Possible working days in a year

$\mathrm{B}=$ Number of days off for public holidays in a year

$\mathrm{C}=$ Number of days off for annual leave in a year

$\mathrm{D}=$ Number of days off due to sick leave

$E=$ Number of days off due to other leaves

$\mathrm{F}=$ Number of working hours in one day 
In the year 2014, there were 52 weeks. Considering 6 working days in one week, there were 312 working days available for LHWs working in Khanpur UC in the year 2014. About 30 days were not available due to various reasons. The details are depicted in Table 2 . In total, about 1,974 hours were available per person in the year 2014.

Table 2. Calculating Non-Available Working Days in a Year

\begin{tabular}{|l|c|c|}
\hline \multicolumn{1}{|c|}{ Reasons for Absence } & Holidays & Availed \\
\hline Public Holidays & 15 & 15 \\
\hline Annual + Casual leave & 20 & 0 \\
\hline Sick leave + Maternity Leave & 15 & 15 \\
\hline Other leave training, personal, Umrah* etc. & 0 & 0 \\
\hline Total Annual Days Absent & $\mathbf{3 0}$ \\
\hline
\end{tabular}

Source: Authors' calculations.

Note: * Umrah is a religious activity.

Step 5: Calculation of the LHWs required for the present workload

The Staffing Requirement of LHWs was calculated using the WISN formula given by Shipp (1998):

\section{Total Staff requirement $=$ \\ Basic staff requirements * Category allowance factor + Individual Allowance Standards}

Basic staff requirements are the requirements the staff is needed to cope with during the annual workload given in statistics and is given by:

$$
\text { Basic staff requirements }=\frac{\text { Annual workload }}{\text { Standard workload }}
$$

Standard workload is the quantum of work done during the delivery of health services during the period of one year by members of staff category to adequate professional standards in a local environment. It is calculated as follows:

$$
\text { Standard workload }=\frac{\text { Available working time in ayear (AWT) }}{\text { Activity standard }}
$$

After knowing the AWT and setting the allowance standards, the standard workload and subsequently the basic staff requirements were calculated. The results from basic staffing requirements were then multiplied with the category allowance factor, also known as the intermediate staff requirements. The category allowance factor is given by (Shipp 1998):

$$
\text { Category allowance factor }=\frac{1}{[1-(\text { Total } \% \text { Category Allowance Standards })]}
$$


Initially activity allowance standards were set on a daily, weekly, monthly or annual basis based on the type of activities performed. These standards were then converted into percentages in order to standardize them. Summing up these individual standards resulted in a category allowance multiplier. The total Individual allowance standards (IAS) were added to the intermediate staff requirements in order to get the total staff requirements i.e. the number of staff required to cope with the annual workload reflected in the statistics.

Step 6: Calculation of the WISN ratio for the workload pressure of LHWs

Following are the two ways in which WISN results can be analyzed:

1. Difference: With the help of difference measure, one can identify understaffing or overstaffing conditions in health facilities.

2. Ratio: WISN ratio helps in assessing the work pressure experienced by heath workers at work in a health facility.

The present LHWs numbers were obtained from the Lady Health Supervisor (LHS) for 2014. The WISN ratio is calculated as follows:

$$
\text { WISN Ratio }=\frac{\text { Current Number of Staff }}{\text { Required Number of Staff }}
$$

A WISN ratio of one shows balanced current staffing. A WISN ratio greater than one shows overstaffing. Conversely, a WISN ratio falls below one when current staffing is inadequate to cope with the present workload. The greater the WISN ratio, the smaller the work pressure and vice versa. The workload pressure was calculated using the following formula:

$$
\text { Workload pressure } \%=(1-\text { WISN ratio }) \times 100
$$

\section{Results}

The AWT for an LHW in 2014 was about 312 days which equals to about 1,974 working hours. A LHW requires about 245 minutes per day to visit 07 households. Using the information about time spend on each activity, CAS and IAS, required for Support Services Activity and Additional Allowance Activity were calculated, respectively, as illustrated in Table 3. As per WISN calculation, the basic staff required for health service activities came out to be 0.596, CAF 1.085 and IAF 0.187. The current number of LHWs was 16 while the total required number of staff based on WISN was 13. The difference between the number of LHWs deployed and required was evidence that LHW staffing in Khanpur UC is not in balance with its workload, as depicted in the statistics for 2014. It was relatively overstaffed having 03 LHWs in surplus compared to LHW staffing requirement calculated based on the WISN method. The WISN ratio measure came out to be 1.1989 , given in Table 4, which provided evidence that LHWs staffing requirement and workload were not in balance in Khanpur UC. Workload pressure was also $-19.89 \%$ which showed 
that LHWs were not under workload pressure. As per assigned duties, one LHW was expected to visit 07 households daily. WISN results were projected to achieve WISN ratio of one using the number of households as a criteria to achieve balanced workload pressure. Projected results showed that workload pressure can be stabilized by increasing the number of households from 07 to 09, as illustrated in Table 5.

\section{Discussion}

Analysis of the workload of LHWs in Khanpur UC for one year (January 2014-Decemeber 2014) showed that workload was fairly unstable that means staffing requirement and workload were not in balance. LHWs were in surplus as compared to UC's staff requirement and underutilized which means they were not under any workload pressure. Even one LHW was utilizing only $80.11 \%$ of her AWT in providing services to the population. The same was true for all 16 LHWs on duty. Hence in effect, work pressure of even only one LHW came down to negative i.e. $-19.89 \%$. While at the same time, 12,500 population in the same UC was unserved. The WISN ratio of one could be achieved if the number of households visited per LHW per day increased from 07 to 09 . This would bring the balance between the current staffing and their work.

WISN results for the year 2014 suggested the redistribution of LHWs to the areas which were unserved or under-served in Khanpur UC so that the work pressure gets fairly distributed among all LHWs. This would make a more appropriate and efficient utilization of LHW staff. Only 13 LHWs can perform the same amount of work currently assigned to the present 16 LHWs. The reasons for existence of extra 3 LHWs in the area might be a centralized planning for whole country on uniform parameters without taking into consideration the variations in topography and the climate of various regions which creates an impact on the travel time to perform the assigned duty. These three can be redistributed in the uncovered area which can increase provision of health services there and improve health conditions. In this way, the unmet health services requirement of the remaining unserved populations can also be achieved. This will help with the promotion of primary health care through equal distribution of LHWs among the population of Khanpur, UC to carry out the activities identified by the experts working group.

This study has few limitations as time standards of the LHWs activities were calculated based on the information recorded by LHWs and by interviewing them, not through time/motion observation. Actual time requirements or number of household visit on a daily basis may vary in other regions, for a variety of reasons. We conducted this study by considering centralized planning for a whole country on uniform parameters without taking into consideration the variations in topography and the climate of various regions which may create an impact on the travel time to perform the assigned duty. This study was conducted in an area with a population limited to 20,000, and for LHWs services only. Other possibilities of observation like consideration of topography, weather etc. may have generated different conclusions. 
Table 3. Calculating Staff Requirement using WHO's WISN Tool

\begin{tabular}{|c|c|c|c|c|c|}
\hline & Workload Component & $\begin{array}{l}\text { Workload } \\
\text { (households) }\end{array}$ & $\begin{array}{c}\text { Annual } \\
\text { Workload } \\
\text { (households) } \\
\end{array}$ & $\begin{array}{l}\text { Standard } \\
\text { Workload }\end{array}$ & $\begin{array}{l}\text { Required number of } \\
\text { staff members }\end{array}$ \\
\hline $\begin{array}{l}\text { Health service } \\
\text { activities of } \\
\text { LHWs }\end{array}$ & Visits to households & 168 & 2016 & 3384 & 0.596 \\
\hline \multicolumn{4}{|c|}{ A: Basic required staff for health service activities } & \multicolumn{2}{|r|}{0.596} \\
\hline & \multicolumn{3}{|c|}{ Workload component } & $\begin{array}{c}\text { CAS (Actual } \\
\text { Working time) }\end{array}$ & $\begin{array}{l}\text { CAS (Percentage } \\
\text { working time) }\end{array}$ \\
\hline \multirow{4}{*}{$\begin{array}{l}\text { Support } \\
\text { activities of } \\
\text { LHWs }\end{array}$} & \multicolumn{3}{|l|}{ 2. Meeting of the Women committee } & 4.898 & 1.166 \\
\hline & \multicolumn{3}{|l|}{ 3. School Visit ( approximately 03 schools ) } & 7.347 & 1.749 \\
\hline & \multicolumn{3}{|c|}{ 4. Report to the THQ } & 17.143 & 4.082 \\
\hline & \multicolumn{3}{|c|}{ 5. Supervisory visits and coordinating district and tehsil management $30 \mathrm{~min} / \mathrm{month}$ (6 hours) } & 1.224 & 0.292 \\
\hline \multicolumn{5}{|c|}{ Total CAS percentage } & 7.872 \\
\hline \multicolumn{5}{|c|}{ B. Category allowance factor: $\{1 /[1-($ total CAS percentage/100) $]\}=$} & 1.085 \\
\hline & Workload components & $\begin{array}{c}\text { Number of staff } \\
\text { members performing } \\
\text { the work }\end{array}$ & $\begin{array}{l}\text { Days per } \\
\text { annum }\end{array}$ & $\begin{array}{c}\text { Available } \\
\text { working hours } \\
\text { per day } \\
\end{array}$ & $\begin{array}{l}\text { IAS (Actual working } \\
\text { time per person) }\end{array}$ \\
\hline \multirow{4}{*}{$\begin{array}{l}\text { Additional } \\
\text { activities of } \\
\text { LHWs }\end{array}$} & 1. MNCH Programme & 1 & 6 & 7 & 42 \\
\hline & 2. Measles Campaign & 1 & 14 & 7 & 98 \\
\hline & 3. Polio campaign & 1 & 32 & 7 & 224 \\
\hline & $\begin{array}{l}\text { 4. Giving information to researchers, academicians } \\
\text { etc. } 6 \text { hours ( } 30 \text { minutes/month) }\end{array}$ & 1 & 0.857 & 7 & 6 \\
\hline \multicolumn{5}{|c|}{ Total IAS in a year = } & 370 \\
\hline \multicolumn{5}{|c|}{ C. Individual allowance factor ( Annual total IAS/ AWT) = } & 0.187 \\
\hline \multicolumn{5}{|c|}{ Total required number of staff based on WISN: $(A * B+C)=$} & 0.834 \\
\hline
\end{tabular}

Source: Authors' calculations.

Note: WISN tool provides health managers a systematic way to make staffing decisions in order to manage their valuable human resources well. It is a tool designed in a manner that it accommodates various indicators in different units i.e. IAS, CAS etc. The method is approved by the World Health Organization for the calculation of Work Load, Work Pressure and Staffing Needs. Hence the units given there for calculation of IAS \& CAS were used accordingly. 
Table 4. Analyzing WISN Results

\begin{tabular}{|c|c|c|c|c|c|c|c|}
\hline $\begin{array}{c}\text { Current number of } \\
\text { staff }\end{array}$ & $\begin{array}{c}\text { Total staff required } \\
\text { based on WISN }\end{array}$ & $\begin{array}{c}\text { Required number } \\
\text { based on WISN }\end{array}$ & $\begin{array}{c}\text { Shortage } \\
\text { or excess* }\end{array}$ & $\begin{array}{c}\text { Workforce } \\
\text { Problem }\end{array}$ & $\begin{array}{c}\text { WISN } \\
\text { Ratio*** }\end{array}$ & $\begin{array}{c}\text { Workload } \\
\text { Problem }\end{array}$ & $\begin{array}{c}\text { Workload } \\
\text { pressure }\end{array}$ \\
\hline 1 & 0.834 & 0.834 & 1 & Surplus & 1.1989 & Low & -19.89 \\
\hline 16 & 0.834 & 13.345 & 3 & Surplus & 1.1989 & Low & -19.89 \\
\hline
\end{tabular}

Source: Authors' calculations.

Notes: *Difference Measure, **When staff requirement meets demand, the WISN ratio is 1.0; when demand exceeds supply, the WISN ratio falls below 1.0. LHWs shortage or surplus can be identified by the deviation of ratio number from 1.0.

Table 5. Projected WISN Result on Varying the Number of the Households

\begin{tabular}{|c|c|c|c|c|c|c|c|c|}
\hline Household & $\begin{array}{c}\text { Actual } \\
\text { Workload }\end{array}$ & $\begin{array}{c}\text { Standard } \\
\text { Workload }\end{array}$ & $\begin{array}{c}\text { Staff } \\
\text { Required }\end{array}$ & CAF & $\mathbf{I A F}$ & $\begin{array}{c}\text { Staff required based } \\
\text { on WISN }\end{array}$ & $\begin{array}{l}\text { WISN } \\
\text { Ratio }\end{array}$ & $\begin{array}{l}\text { Workload } \\
\text { Pressure }\end{array}$ \\
\hline 7 & 2016 & 3384 & 0.596 & 1.085 & 0.187 & 0.834 & 1.199 & Low \\
\hline 8 & 2304 & 3384 & 0.681 & 1.085 & 0.187 & 0.927 & 1.079 & Low \\
\hline 9 & 2592 & 3384 & 0.766 & $\mathbf{1 . 0 8 5}$ & 0.187 & 1.019 & 0.982 & Normal \\
\hline 10 & 2880 & 3384 & 0.851 & 1.085 & 0.187 & 1.111 & 0.899 & High \\
\hline 11 & 3168 & 3384 & 0.936 & 1.085 & 0.187 & 1.204 & 0.831 & High \\
\hline
\end{tabular}

Source: Authors' calculations. 
The strength of the study is that the research team comprised of people trained in data collection and familiar with the services of this cadre. Limiting our scope of study to LHW services allowed a realistic estimation of staffing requirement in Khanpur, since the information in the study area was routinely recorded and relatively accurate. Therefore, the data collected was found to be relatively reliable, as there were good records of health activities performed by existing LHWs in the area under study

\section{Conclusions}

This study was conducted with the aim to assess the LHWs presently working in Khanpur UC, Khyber Pakhtunkhwa, comprising of 4,200 households. 16 LHWs have been deployed to serve 112 households per day i.e. 7 households by each LHW per day. About 2,688 households are covered per month while 1,512 households are left unattended. LHWs shortage was identified by the lady health supervisor (LHS) to cover the entire population of the Union Council on a household basis.

Based on the size of the workload of LHWs in Khanpur UC for one year (January 2014-Decemeber 2014), it is concluded that staffing requirement and workload were not in balance. LHWs were found under no workload pressure. While at the same time, 12,500 people of the population in the same UC was identified unserved.

The main fall back of the study was that the results are not generalizable to other areas and regions due to the specific topography of the study area. Therefore, a national study is being proposed. Moreover, a study can be conducted to understand the reasons of the uneven distribution of the resources and workload. The exercise should be carried out periodically as a part of the policy by the Federal Government to assess the workload not only for LHWs but for all cadres in the providing health services.

\section{Recommendations}

The management staff of LHWs in the Khanpur UC is advised to redistribute the present underutilized LHWs in the uncovered areas and increase the number of households to be visited per LHW from 07 to 09 per day so that the workload pressure inequalities could be evened out and the human resources management problems in the area could be better solved. Considering their shortage as identified by the LHS, management is needed to consider the recruitment of 05 more LHWs instead of 09. 


\section{Acknowledgments}

We would like to thank LHWs, LHS and the staff of the Tehsil Headquarters (THQs) of Khanpur, Khyber Pakhtunkhwa Province, Pakistan for giving us their time generously. This is a pilot study i.e. a small scale preliminary study conducted in order to evaluate feasibility in an attempt to predict and improve upon the study design prior to the performance of a fullscale research project for which this preliminary study is being conducted. This pilot study is part of the country level project being planned by the Health Services Academy (HSA) in Islamabad in collaboration with the United Nations Fund for Population Activities (UNFPA) to assess the quantum of workload on LHWs in Pakistan. We are also thankful Deutsche Gesellschaft fur Internationale Zusammenarbeit (GIZ), GmbH to sponsor the participation of 1st Author for presenting this work in 14th Annual International Conference on Health Economics, Management \& Policy, 22-25 June 2015, Athens, Greece.

\section{References}

Buchan J (1999) Determining Skill Mix: An International Review. World Health Organisation.

Buchan J, Ball J, May FO (2000) Skill Mix in the Health Workforce: Determining Skill Mix in the Health Work Force: Guidelines for Managers and Health Professionals. Retrieved from: http://goo.gl/NdDbxf. [Accessed: 6 April 2015]

Das S, Manna N, Datta M, Sengupta D, Samsuzzaman MD, Baur B, Padmaja Vasi MBBS (2013) A study to calculate the nursing staff requirement for the Maternity Ward of Medical College Hospital, Kolkata Applying WISN method. Planning 5: 167-176.

Daviaud E, Chopra M (2008) How much is not enough? Human resources requirements for primary health care: a case study from South Africa. Bulletin of the World Health Organization 86: 1.

Delanyo D (2005) Wastage in the Health Workforce: Some Perspectives from African Countries. Retrieved from http://goo.gl/3kXJgz. [Accessed: 24 April 2015]

Hafeez A, Mohamud BK, Shiekh MR, Shah SAI, Jooma R (2011) Lady health workers programme in Pakistan: challenges, achievements and the way forward. JPMA-Journal of the Pakistan Medical Association 61(3): 210.

Hagopian A, Mohanty MK, Das A, House PJ (2012) Applying WHO's Workforce Indicators of Staffing Need (WISN) method to calculate the health worker requirements for India's maternal and child health service guarantees in Orissa State. Health Policy and Planning 27(1): 11-18.

Hossain B, Alam SA (1999) Likely benefit of using workload indicators of staffing need (WISN) for human resources management and planning in the health sector of Bangladesh. Human Resources Development Journal 3(2): 99-111.

Hurst K (2006) Primary and community care workforce planning and development. Journal of Advanced Nursing 55: 757-769.

Khan AW, Amjad CM, Hafeez A, Shareef R (2012) Perceived individual and community barriers in the provision of family planning services by lady health 
workers in Tehsil Gujar Khan. Journal of the Pakistan Medical Association 62(12): 1318-1322.

Khan A (2011) Lady health workers and social change in Pakistan. Economic and Political Weekly XLVI(30): 28-31.

Kolehmainen-Aitken RL, Shipp P (1990) Indicators of staffing need: assessing health staffing and equity in Papua New Guinea. Health Policy and Planning 5(2): 167-176.

Kolehmainen-Aitken RL (2009) A WISN Toolkit: A Toolkit for Implementing Workload Indicators of Staffing Need (WISN) to Improve Health Workforce Planning and Management in Decentralized Health Systems. Jakarta, GTZ/EPOS HRD in the Health Sector Project Indonesia.

Mugisha JF, Namaganda G (2008) Using the Workload Indicator of Staffing Needs (WISN) methodology to assess work pressure among the nursing staff of Lacor Hospital. Health Policy and Development 6(1).

Musau P, Nyongesa P, Shikhule A, Birech E, Kirui D, Njenga M, Mbiti D, Bett A, Lagat L, Kiilu K (2008) Workload indicators of staffing need method in determining optimal staffing levels at Moi Teaching and Referral Hospital. East African Medical Journal 85: 232-239.

Namaganda G (2004) Determining staffing levels and mix of UCMB affiliated hospitals. Health Policy and Development 2(3).

Sarfraz M, Hamid S (2014) Challenges in delivery of skilled maternal care-experiences of community midwives in Pakistan. BMC Pregnancy Childbirth 14: 59.

Schoo AM, Boyce RA, Ridoutt L, Santos T (2008) Workload capacity measures for estimating allied health staffing requirements. Australian Health Review 32: 548-558.

Shaikh BT, Hatcher J (2004) Health seeking behavior and health service utilization in Pakistan: challenging the policy makers. Journal of Public Health 27(1): 49-54.

Shipp PJ (1998) Workload Indicators of Staffing Need (WISN): A Manual for Implementation. Geneva, Switzerland: WHO Division of Human Resources Development and Capacity Building.

Wajid A, White F, Karim MS (2013) Community health workers and health care delivery: evaluation of a women's reproductive health care project in a developing country. PLOS ONE 8(9): e75476.

WHO-World Health Organization (2010) Workload Indicators of Staffing Needs (WISN): User Manual. Geneva. Retrieved from http://goo.gl/oysD2D. [Accessed: 6 April. 
